\title{
Feasibility and safety of minimal-incision thyroidectomy for Graves' disease: A prospective, single-center study
}

\author{
Giuliano Perigli, MD, ${ }^{1}$ Etleva Qirici, MD, ${ }^{1}$ Benedetta Badii, MD, ${ }^{1}$ Aurora Kokomani, MD, ${ }^{1}$ Fabio Staderini, MD, ${ }^{1}$ Michaela Luconi, MD, ${ }^{2}$ \\ Clara Crescioli, MD, ${ }^{3}$ Massimo Mannelli, MD, ${ }^{2}$ Mario Maggi, MD, ${ }^{2}$ Fabio Cianchi, MD ${ }^{1 *}$ \\ ${ }^{1}$ Department of Medical and Surgical Critical Care, Medical School, University of Florence, Florence, Italy, ${ }^{2}$ Department of Clinical Physiopathology, \\ University of Florence, Florence, Italy, ${ }^{3}$ Department of Health Sciences, University of Rome Foro Italico, Rome, Italy.
}

Accepted 12 June 2012

Published online in Wiley Online Library (wileyonlinelibrary.com). DOI 10.1002/hed.23125

\begin{abstract}
Background. The role of minimally invasive surgery in Graves' disease is still controversial. The aim of this study was to compare the clinical outcomes of patients undergoing minimal-incision thyroidectomy with those undergoing conventional thyroidectomy for Graves' disease.

Methods. A prospective study was performed on 148 patients undergoing total thyroidectomy. Seventy-one patients underwent minimal-incision thyroidectomy and 77 underwent conventional thyroidectomy. Minimal-incision thyroidectomy was proposed if the thyroid volume was $\leq 50 \mathrm{~mL}$.

Results. There were no significant differences in the operative time between minimal-incision thyroidectomy and conventional thyroidectomy. The length of
\end{abstract}

skin incision was significantly shorter in the minimal-incision thyroidectomy than that in the conventional thyroidectomy group. The incidence of postoperative complications was similar in the 2 groups. Patients undergoing minimal-incision thyroidectomy experienced significantly less postoperative pain and were more satisfied with the cosmetic result than patients who underwent conventional thyroidectomy.

Conclusions. Minimal-incision thyroidectomy is a feasible and safe option for the surgical treatment of selected patients with Graves' disease. (c) 2012 Wiley Periodicals, Inc. Head Neck 00: 000-000, 2012

KEY WORDS: thyroid, Graves' disease, minimally invasive surgery, minimal-incision thyroidectomy, postoperative complications

\section{INTRODUCTION}

Current treatment of Graves' disease is based on antithyroid drugs, radioactive iodine, and surgery. Medical management is generally the first choice, whereas surgery is recommended to patients who either refuse radioactive iodine or experience disease recurrence after previous drug or iodine treatment. Large glandular volume, suspect of malignancy, young age, severe ophthalmopathy, and pregnancy are the other main indications for surgery. 1,2

Total thyroidectomy is considered the standard surgical procedure for Graves' disease by several authors. ${ }^{3-6}$ The advantages of a radical operation as compared with less than total thyroidectomy may be the following: (1) no risk of disease recurrence and, thus, no risk of increased morbidity associated with secondary operation; (2) better control of immunological disorder with possible beneficial effect on ophthalmopathy; (3) adequate treatment of incidental thyroid malignancy; and (4) easier L-tiroxine substitution in the athyroid patient. Importantly, it has

*Corresponding author: F. Cianchi, Department of Medical and Surgical Critical Care, Medical School, University of Florence, Florence, Italy.

E-mail: fabio.cianchi@unifi.it

Contract grant sponsor: Italian Ministry of University, Scientific and

Technological Research; contract grant sponsor: Ente Cassa di Risparmio di

Firenze. been shown that the morbidity and cosmetic impact of cervical incision after total thyroidectomy are comparable to those of subtotal thyroidectomy. ${ }^{7-9}$

Recently, minimally invasive surgery has been successfully used for the treatment of both benign and malignant thyroid disorders. The well-known advantages of this approach are the reduced postoperative pain, improved cosmesis (patients are usually young females), shorter hospital stay, and lower costs. ${ }^{10-16}$ However, the role of minimally invasive surgery techniques in the treatment of Graves' disease is still uncertain. This is mainly due to increased glandular vascularity and frequent periglandular inflammation, resulting in potential technical difficulties and an increased incidence of complications. ${ }^{17}$

The aim of this study was to compare the efficacy and safety of open, nonendoscopic minimal-incision thyroidectomy with that of conventional thyroidectomy in the treatment of patients with Graves' disease.

\section{MATERIALS AND METHODS}

\section{Patients}

Between October 2002 and December 2009, 189 consecutive patients with a confirmed diagnosis of Graves' disease underwent total thyroidectomy by the same surgeon at the Endocrine and Minimally Invasive Surgery Unit of the University of Florence, Italy. In all, 148 of these 189 patients were enrolled in this prospective, 
TABLE 1. Indications for surgery.

\begin{tabular}{llc}
\hline & \multicolumn{2}{c}{ No of patients (\%) } \\
\cline { 2 - 3 } Factor & MIT $(n=71)$ & CT $(n=77)$ \\
\hline $\begin{array}{l}\text { Failed medical treatment } \\
\text { Recurrent hyperthyroidism after }\end{array}$ & $57(80.2)$ & $62(80.5)$ \\
$\quad$ medical treatment & $12(16.9)$ & $4(5.1)$ \\
$\begin{array}{l}\text { Adverse effects of medical treatment } \\
\text { Patient's choice }\end{array}$ & $1(1.4)$ & $3(3.8)$ \\
$\begin{array}{l}\text { Thyroid volume responsible for } \\
\quad \text { compressive symptoms }\end{array}$ & $1(1.4)$ & $0(0)$ \\
Severe ophthalmopathy & $0(0)$ & $4(5.1)$ \\
\hline
\end{tabular}

Abbreviations: MIT, minimal-incision thyroidectomy; CT, conventional thyroidectomy.

nonrandomized study: 71 patients (64 female, 7 male; mean age, $41.4 \pm 1.4$ years) underwent minimal-incision thyroidectomy, whereas the remaining 77 patients (56 female and 21 male; mean age, $46.4 \pm 1.3$ years) underwent conventional thyroidectomy and formed a control group. Patients were selected for minimal-incision thyroidectomy if the thyroid volume was $\leq 50 \mathrm{~mL}$ measured by means of ultrasonography. All patients were treated with an antithyroid drug and/or $\beta$-blockers before surgery until stable clinical and serologically proven euthyroidism was achieved. All patients had been thoroughly informed about the study and gave written consent for the investigation in accord with the ethical guidelines of our university.

The indications for surgery are shown in Table 1 .

\section{Surgical technique}

Minimal-incision thyroidectomy is an open, nonendoscopic procedure and was performed in accord with the methods previously described. ${ }^{18}$ Briefly, a $2.5-$ to $3.5-\mathrm{cm}$ incision in a central skin crease of the neck is made approximately $3 \mathrm{~cm}$ above the sternal notch. A minimal subplatysmal flap is made and the cervical linea alba is divided longitudinally for at least $3 \mathrm{~cm}$. Strap muscles of the affected side are retracted with small conventional retractors. Blunt dissection of the lateral aspect of the thyroid, including division of the middle thyroid vein, division of the superior thyroid artery and vein, and identification of the recurrent laryngeal nerves and parathyroid glands are performed with the aid of an additional head light source and the use of traditional tiny surgical instruments. Vessels are divided between conventional ligatures. Wound closure includes platysma and skin with reabsorbable sutures.

Conventional thyroidectomy is performed through a 4.5- to 8-cm transverse cervical incision. Subplatysmal flaps are extended to the level of the hyoid bone and inferiorly to the sternal notch. After separating and laterally retracting the strap muscles, the gland is removed in a fashion similar to that reported for minimal-incision thyroidectomy. Drains were placed in both groups.

Preoperative and postoperative (6 and 18 hours after the operation) serum calcium levels (normal range, 8.2-10.7 $\mathrm{mg} / \mathrm{dL}$ ) were assessed in all patients. Hypocalcemia was distinguished as asymptomatic or symptomatic. On the first postoperative day, laryngoscopy was performed to check vocal cord motility in all patients. Generally, patients were discharged on the first postoperative day with oral levothyroxine substitution therapy. Oral calcium and vitamin D supplementation were administered only when hypocalcemia developed.

Operative outcomes, postoperative complications, and final pathologic report were recorded. Postoperative pain was assessed by means of a visual analogue scale (VAS). This scale consisted of a $10-\mathrm{cm}$ line with the words no pain on the left side, at zero, and worst pain imaginable on the right side, at 10 . All patients were asked to evaluate their pain 6 and 18 hours after the operation by indicating its level on the line. Cosmetic results were evaluated with a numerical score system (NSS) ranging from 0 to 10 . The patients were asked to grade the cosmetic appearance of their wound 1 month after surgery.

\section{Statistical analysis}

Categorical variables within the minimal-incision thyroidectomy and conventional thyroidectomy groups were compared using Fisher's exact test or the chi-square test. Quantitative variables were summarized by mean \pm SEM. Differences in these parameters between the 2 study groups were compared using the Mann-Whitney test. Statistical analysis was performed using Stata Statistical Software (release 5.0; Stata Corporation, College Station, TX). Probability was determined using 2-sided statistical tests, with $p<.05$ considered statistically significant.

\section{RESULTS}

Patients underwent surgery after an average of $2.3 \pm$ 1.2 and $2.8 \pm 1.5$ months of preoperative medical preparation in the minimal-incision thyroidectomy and in the conventional thyroidectomy group, respectively ( $p=$ not significant $[\mathrm{NS}]$ ).

Table 2 summarizes the main operative outcomes in the 2 groups. There were no significant differences in the operative time between the 2 procedures. No patient in the minimal-incision thyroidectomy group required conversion to conventional thyroidectomy. In only 3 patients was the initial skin incision extended for another $10 \mathrm{~mm}$ to allow the extraction of glands of critical volume. In these cases we used the final length for statistical

TABLE 2. Outcomes after surgical treatment.

\begin{tabular}{llll}
\hline Characteristic & $\begin{array}{l}\text { MIT } \\
(n=71)\end{array}$ & $\begin{array}{l}\text { CT } \\
(n=77)\end{array}$ & $p$ value \\
\hline Incision length, mm & $31.3 \pm 0.8$ & $53.5 \pm 2.5$ & $<.001$ \\
Mean operative time, min & $61.6 \pm 4.6$ & $65.8 \pm 4.8$ & $\mathrm{NS}$ \\
Mean glandular volume, mL & $39.4 \pm 3.0$ & $53.7 \pm 2.9$ & $<.001$ \\
Estimated blood loss, mL & $22.9 \pm 6.9$ & $32.8 \pm 6.7$ & $\mathrm{NS}$ \\
Hospital stay, h & $28.2 \pm 2.0$ & $28.2 \pm 2.5$ & $\mathrm{NS}$ \\
$\begin{array}{l}\text { Postoperative pain (VAS: 1-10) } \\
\text { 6 h }\end{array}$ & $4.3 \pm 0.6$ & $8.3 \pm 0.4$ & $<.05$ \\
$\quad$ 18 h & $1.2 \pm 0.4$ & $3.2 \pm 0.4$ & $<.05$ \\
Cosmetic satisfaction & $8.4 \pm 0.3$ & $3.8 \pm 0.9$ & $<.05$ \\
$\quad$ (NSS: 1-10) & & & \\
Incidental carcinoma, no. (\%) & $7(9.8 \%)$ & $4(5.1 \%)$ & $\mathrm{NS}$ \\
\hline
\end{tabular}

Abbreviations: MIT, minimal-incision thyroidectomy; CT, conventional thyroidectomy; VAS, visual analogue scale; NSS, numerical score system; NS, not significant. 
TABLE 3. Postoperative complications.

\begin{tabular}{llll}
\hline & \multicolumn{3}{c}{ No of patients (\%) } \\
\cline { 2 - 4 } Complication & MIT $(n=71)$ & CT $(n=77)$ & $p$ value \\
\hline $\begin{array}{l}\text { Transient asymptomatic } \\
\quad \text { hypocalcemia }\end{array}$ & $10(14.0)$ & $7(9.0)$ & NS \\
$\begin{array}{c}\text { Transient symptomatic } \\
\quad \text { hypocalcemia }\end{array}$ & $8(11.2)$ & $5(6.4)$ & NS \\
$\begin{array}{l}\text { Permanent hypoparathyroidism } \\
\text { Transient cord palsy }\end{array}$ & $0(0)$ & $0(0)$ & NS \\
$\begin{array}{l}\text { Permanent cord palsy } \\
\text { Bleeding }\end{array}$ & $4(5.6)$ & $2(2.5)$ & NS \\
\hline
\end{tabular}

Abbreviations: MIT, minimal-incision thyroidectomy; CT, conventional thyroidectomy; NS, not significant.

analysis. The final length of skin incision was significantly shorter in the minimal-incision thyroidectomy than that in the conventional thyroidectomy group $(31.3 \pm 0.8$ vs $53.5 \pm 2.5 \mathrm{~mm}, p<.001)$. The mean glandular volume was significantly lower in the minimal-incision thyroidectomy than that in the conventional thyroidectomy group, whereas there were no significant differences in the estimated blood loss between the 2 groups. The patient's hospital stay did not significantly differ between the 2 groups. Importantly, patients undergoing minimalincision thyroidectomy experienced significantly less postoperative pain and were more satisfied with the cosmetic result than patients who underwent conventional thyroidectomy.

Pathologic examination of the surgical specimens confirmed Graves' disease in all patients and revealed incidental papillary microcarcinoma in 7 patients $(9.8 \%)$ in the minimal-incision thyroidectomy and in 4 patients $(5.1 \%)$ in the conventional thyroidectomy groups (Table 2).

No statistically significant differences were observed between the 2 groups with regard to postoperative complications. In particular, asymptomatic hypocalcemia occurred in 10 patients $(14.0 \%)$, transient symptomatic hypocalcemia in 8 patients $(11.2 \%)$, permanent hypoparathyroidism in none, transient cord palsy in 4 patients $(5.6 \%)$, and permanent cord palsy in 2 patients $(2.8 \%)$ in the minimal-incision thyroidectomy group compared with 7 patients $(9.0 \%), 5$ patients $(6.4 \%), 0$ patients, 2 patients $(2.5 \%)$, and 2 patients $(2.5 \%)$ in the conventional thyroidectomy group, respectively (Table 3 ). Only 1 patient in both groups had early postoperative bleeding, which required reoperation ( $p=\mathrm{NS}$ ) (Table 3 ).

\section{DISCUSSION}

Because medical and radioactive iodine treatment are limited by long-lasting and unpredictable late results, some authors have proposed surgery as the treatment of choice for Graves' disease. ${ }^{1-4}$ Two recent evidence-based studies have better defined the prominent role of surgery and its safety. 5 .6 Patients may especially benefit from total thyroidectomy for the immediate relief of the hyperthyroidism, easy hormonal substitution, the absence of risk of disease recurrence, frequent improvement in both ophthalmopathy and humoral autoimmunity, and a complete pathologic examination of the gland. Nevertheless, medical and radioactive iodine treatments are still superior to surgery in terms of cosmetic results and incidence of complications.

Surgery has recently improved due to the advent of minimally invasive procedures. Several techniques have been proposed that would allow minimal surgical access to the thyroid gland. These include totally endoscopic thyroidectomy with $\mathrm{CO}_{2}$ insufflation into the neck (with anterior cervical approach, breast approach, or transaxillary approach), ${ }^{19-22}$ video-assisted thyroidectomy (VAT) ${ }^{11,13,14,23}$ open nonendoscopic minimal-incision thyroidectomy, ${ }^{15,16,18}$ and, more recently, robotic thyroidectomy. ${ }^{24}$ Although minimally invasive surgery has been used to treat several types of thyroid disorders, the increased gland vascularity in toxic diffuse goiter was first considered a relative contraindication to the minimally invasive approach because of the potential technical difficulty and thus the high incidence of complications in the presence of bleeding. However, Berti and colleagues in $2004,{ }^{17}$ Maeda and colleagues in $2006,{ }^{25}$ and, more recently, Alesina and colleagues in $2011^{26}$ have demonstrated that VAT is feasible and safe for the treatment of Graves' disease, with results equivalent to those of conventional open surgery. The minimal length of surgical incision $(1.5-3 \mathrm{~cm})$ is a key advantage of VAT in comparison with conventional thyroidectomy but at the same time is the main limitation of this type of surgery. Indeed, only glands with volumes $\leq 25 \mathrm{~mL}$ have been treated by Berti and colleagues, ${ }^{17}$ whereas a maximum glandular volume of $30 \mathrm{~mL}$ was established by Alesina and colleagues $^{26}$ for their VAT patients. This implies that only $9 \%$ of patients in Berti's series and $31 \%$ of patients in Alesina's series could be given this technique.

We have previously shown that minimal-incision thyroidectomy, that is, an open thyroidectomy performed through a $2.5-$ to $3.5-\mathrm{cm}$ incision, is safe and effective in treating various thyroid disorders, in particular multinodular goiter, with a gland volume $<80 \mathrm{~mL}$ being the only limiting factor. ${ }^{18}$ We have demonstrated that results of this procedure in terms of cosmetic satisfaction and postoperative pain were significantly better when compared with conventional thyroidectomy and, interestingly, were comparable with those obtained after VAT. ${ }^{18}$ In the present study, we focused our analysis only on patients with Graves' disease to establish whether minimal-incision thyroidectomy can be considered safe and feasible even in the treatment of this surgically demanding thyreopathy with the only limiting factor of a gland volume $\leq 50 \mathrm{~mL}$. Although we do not routinely use Lugol's iodine solution to reduce gland vascularity preoperatively, only 1 patient $(1.4 \%)$ in the minimal-incision thyroidectomy group needed reoperation for major postoperative bleeding. Operative times were similar between the 2 study groups, thus demonstrating that minimal-incision thyroidectomy does not require a long learning curve as usually occurs for VAT. ${ }^{12}$ Importantly, the incidences of transient/permanent hypocalcemia and transient/permanent cord palsy after minimal-incision thyroidectomy did not significantly differ from those following conventional thyroidectomy, being comparable with values reported by previously published meta-analysis on total thyroidectomy. ${ }^{27,28}$ Even asymptomatic hypocalcemia occurred with the same 
frequency in the minimal-incision thyroidectomy and conventional thyroidectomy patients. Although our patient groups were not comparable in terms of thyroid volume, these data clearly demonstrate that minimal-incision thyroidectomy can be performed successfully without any increase in the incidence of postoperative complications and patients can be discharged at the first postoperative day as safely as patients who have undergone conventional thyroidectomy.

We also show that minimal-incision thyroidectomy provides significant advantages with regard to postoperative pain and patients' cosmetic satisfaction when compared with conventional thyroidectomy. Although the axillary approach, either endoscopic or robotic, may offer the best cosmetic results among all the minimally invasive procedures proposed for thyroid surgery, it cannot be recommended in patients with bilateral thyroid disorders such as Graves' disease. In addition, all the extracervical approaches cannot be properly defined minimally invasive because of the long operative times and the wide tissue dissection required. ${ }^{22,24}$ Interestingly, we could adopt minimal-incision thyroidectomy in $47.9 \%$ of our patients with Graves' disease, which is a higher proportion than that reported by the above-cited authors for VAT.

Independently of the approach, minimally invasive or conventional, total thyroidectomy is the preferred operation because the rate of persistent or recurrent disease has been reported to be $7.9 \%$ after subtotal resection ${ }^{29}$ without any advantage in terms of persistent nerve palsy and hypothyroidism. Moreover, the 7.4\% (11/148) overall rate of incidental microcarcinomas in our patients represents an additional argument in favor of total thyroidectomy as treatment of Graves' disease.

In conclusion, within the limitations of a nonrandomized analysis, our results indicate that minimal-incision thyroidectomy is a feasible and reliable option for the surgical treatment of selected patients with Graves' disease. In particular, minimal-incision thyroidectomy may provide all the benefits of minimally invasive surgery even to those patients who are not suitable for other minimally invasive techniques such as VAT.

\section{REFERENCES}

1. Mittendorf EA, McHenry CR. Thyroidectomy for selected patients with thyrotoxicosis. Arch Otolaryngol Head Neck Surg 2001;127:61-65.

2. Lowery AJ, Kerin MJ. Grave's opthalmopathy: the case for thyroid surgery. Surgeon 2009;7:290-296.

3. Alsanea O, Clark OH. Treatment of Graves' disease: the advantages of surgery. Endocrinol Metab Clin North Am 2000;29:321-337.
4. Mishra A, Agarwal A, Agarwal G, Mishra SK. Total thyroidectomy for benign thyroid disorders in an endemic region. World J Surg 2001;25: 307-310.

5. Stalberg P, Svensson A, Hessman O, Akerström G, Hellman P. Surgical treatment of Graves' disease: evidence-based approach. World J Surg 2008;32:1269-1277.

6. Pradeep PV, Agarwal A, Baxi M, Agarwal G, Gupta SK, Mishra SK. Safety and efficacy of surgical management of hyperthyroidism: 15-years experience from a tertiary care center in a developing country. World $J$ Surg 2007;31:306-312.

7. Miccoli P, Vitti P, Rago T, et al. Surgical treatment of Graves' disease: subtotal or total thyroidectomy? Surgery 1996;120:1020-1025.

8. Gimm O, Brauckhoff M, Thanh PN, Sekulla C, Dralle H. An update on thyroid surgery. Eur J Nucl Med Mol Imaging 2002;29:S447-S452.

9. Barakate MS, Agarwal G, Reeve TS, Barraclough B, Robinson B, Delbridge LW. Total thyroidectomy is now the preferred option for the surgical management of Graves' disease. Aust N Z J Surg 2002;72:321-324.

10. Miccoli P, Berti P, Raffaelli M, et al. Comparison between minimally invasive video-assisted thyroidectomy and conventional thyroidecotmy: a prospective randomized study. Surgery 2001;130:1039-1043.

11. Miccoli P. Minimally invasive surgery for thyroid and parathyroid diseases. Surg Endosc 2002;16:3-6.

12. Duh Q-Y. Minimally invasive endocrine surgery: standard of treatment or hype. Surgery 2003;134:849-857.

13. Timon C, Miller IS. Minimally invasive video-assisted thyroidectomy: indications and technique. Laryngoscope 2006;116:1046-1049.

14. Lombardi CP, Raffaelli M, Princi P, et al. Video-assisted thyroidectomy: report on the experience of a single center in more than four hundred cases. World J Surg 2006;30:794-800.

15. Ferzli GS, Sayad P, Abdo Z, et al. Minimally invasive, nonendoscopic thyroid surgery. J Am Coll Surg 2001;192:665-668.

16. Rafferty M, Miller I, Timon C. Minimal incision for open thyroidectomy. Otolaryngol Head Neck Surg 2006;135:295-298.

17. Berti P, Materazzi G, Galleri G, Donatini M, Minuto M, Miccoli P. Videoassisted thyroidectomy for Graves'disease. Report of a preliminary experience. Surg Endosc 2004;18:1208-1210.

18. Perigli G, Cortesini C, Qirici E, Boni D, Cianchi F. Clinical benefits of minimally invasive techniques in thyroid surgery. World J Surg 2008;32: 45-50.

19. Terris D, Gourin CG, Chin E. Minimally invasive thyroidectomy: basic and advanced techniques. Laryngoscope 2006;116:350-356.

20. Inabnet WB, Jacob BP, Gagner M. Minimally invasive endoscopic thyroidectomy by a cervical approach. Surg Endosc 2003;17:1808-1811.

21. Ohgami M, Ishii S, Ohmori T, et al. Scarless endoscopic thyroidectomy: breast approach for better cosmesis. Surg Laparosc Endosc Percutan Tech 2000;10:1-4.

22. Ikeda Y, Takami H, Sasaki Y, et al. Endoscopic neck surgery by the axillary approach. J Am Coll Surg 2000;191:336-340.

23. Bellantone R, Lombardi CP, Raffaelli M, Boscherini M, de Crea C, Traini E. Video-assisted thyroidectomy. J Am Coll Surg 2002;194:610-614.

24. Kandil EH, Noureldine SI, Yao L, Slakey DP. Robotic transaxillary thyroidectomy: an examination of the first one hundred cases. J Am Coll Surg 2012;214:558-564.

25. Maeda S, Uga T, Hayashida N, Ishigaki K, Furui J, Kanematsu T. Videoassisted subtotal or near-total thyroidectomy for Graves' disease. $\mathrm{Br} J$ Surg 2006;93:61-66.

26. Alesina PF, Singaporewalla RM, Eckstein A, Lahner H, Walz MK. Is minimally invasive, video-assisted thyroidectomy feasible in Graves' disease? Surgery 2011;149:556-560.

27. Wagner HE, Seiler C. Recurrent laryngeal nerve palsy after thyroid gland surgery. Br J Surg 1994;81:226-228.

28. Thomusch O, Machens A, Sekulla C, Ukkat J, Brauckhoff M, Dralle H. The impact of surgical technique on postoperative hypoparathyroidism in bilateral thyroid surgery: a multivariate analysis of 5846 consecutive patients. Surgery 2003;133:180-185.

29. Palit TK, Miller CC III, Miltenburg DM. The efficacy of thyroidectomy for Graves' disease: a meta-analysis. J Surg Res 2000;90:161-165. 